\title{
TRADUÇÃO
}

\section{Cartas a Gabriel Marcel ${ }^{1}$}

HENRI BERGSON

Tradução de Carina Eduarda Kozera, Caroline de Paula Bueno, Daniel Du Sagrado Barreto Daluz, Elvio Camilo Crestani Junior, Fábio Gabriel Semençato, Felipe Belin, Gustavo Henrique Martins, Lucas dos Santos, Nilson Rodrigo da Silva, Rafaela Ortiz de Salles e Ricardo Rodrigo França.

Revisão final de Prof. Dr. Claudinei Aparecido de Freitas da Silva.

\section{Nota introdutória}

Fruto das oficinas de francês supervisionadas por mim junto ao PET/Filosofia, em 2018, o presente documento que o leitor agora dispõe, em primeira mão, em versão bilíngue, corresponde às quatro Correspondências dirigidas por Henri Bergson (1859-1941) a Gabriel Marcel (1889-1973), por ocasião da publicação de o Journal Métaphysique (Diário Metafísico) deste último, em 1927. Trata-se, como segue, de um testemunho fecundo permeado por grande afeto intelectual entre ambos. Marcel tinha em Bergson uma figura da mais alta estima não só por ter sido diretamente um mestre espiritual cujas cursos assistira na juventude, mas, sobretudo, pela maneira como a obra bergsoniana impacta na tradição francesa junto ao debate filosófico que viria influenciar toda uma geração de intelectuais do porte de um Sartre, Merleau-Ponty, Ricœur, entre outros. A maneira como o pensamento bergsoniano se reflete em muitas das teses de o Journal é um demonstração inconteste disso.

Prof. Dr. Claudinei Aparecido de Freitas da Silva (UNIOESTE)

\section{Lettre 1}

Paris, 32 Rue Vital / 23 mars 1928

Mon cher Collègue,

Laissez-moi d'abord vous dire combien je suis touché de la pensée que vous avez eue de me dédier votre «Journal Métaphysique». Très souffrant depuis un certain temps, ne disposant que de bien peu d'heures pour le travail et obligé alors de liquider un énorme arriére de besogne, je n'ai pu lire votre ouvrage que bien superficiellement. Mais ce premier coup d'œil a suffi à m'en faire mesurer la profondeur et l'importance. J'y vois surtout un vigoureux effort pour poser en termes nouveaux le problème de l'objectivité, ou plutôt de l' existence. Il est vrai que

\footnotetext{
${ }^{1}$ Originalmente "Lettres de Henri Bergson a Gabriel Marcel", em: BERGSON, H. Correspondances. Paris: PUF, 2002, p. 1450.
} 
la forme que vous avez donné à votre pensée, celle d'un "Journal", fait que le lecteur a quelque peine à fixer votre point de vue. Il faudra que je vous relise attentivement. Dès à present il me semble que la philosophie que vous exposez s'appliquerait spécialement à une réalité élargie par la "recherche psychique", par cette métapsychie à laquelle vous faites une place si importante dans la seconde partie du livre. Tous mes compliments, tous mes remerciements, et bien sympathiquement à vous.

\section{H. Bergson}

\section{Carta 1}

Paris, 32 Rue Vital / 23 de março de 1928

Meu caro colega,

Deixe-me, em primeiro lugar, vos dizer sobre o quanto estou tocado pelo pensamento que você tem tido ao me dedicar seu "Diário Metafísico". Muito adoentado após um certo tempo, dispondo apenas de algumas horas para o trabalho e obrigado então a cumprir um enorme volume de tarefa, eu não poderia ler sua obra senão superficialmente. Mas esse primeiro olhar de relance foi o suficiente a fim de poder mensurar a profundidade e importância. Eu vejo, sobretudo, um esforço vigoroso para pôr, em novos termos, o problema da objetividade, ou melhor, da existência. É verdade que a forma que você deu ao seu pensamento, a de um "Diário", torna difícil para o leitor fixar o seu ponto de vista. É preciso que eu vos leia mais atentamente. Desde esse momento presente, parece-me que a filosofia que você expõe se aplicaria especialmente a uma realidade ampliada pela "pesquisa psíquica", por essa metafísica à qual você concede um lugar tão importante na segunda parte do livro. A você, de maneira afetuosa, todos os meus cumprimentos e agradecimentos.

H. Bergson

\section{Lettre 2}

Paris, 9 mai 1934

L' état de ma santé me laisse peu de temps dans ma journée pour travailler et pour écrire. Je n'ai donc pu lire que rapidement et superficiellent, très tardivement aussi, le livre vous avez bien voulu m' adresser: "Le monde cassé" avec "Position du mystère ontologique". Mais cette première lecture, qui devrait être suivie d' une autre plus approfondie, (qui le sera sûrement si je retrouve quelque liberté), a suffi à me montrer l'importance et la valeur des deux œuvres que vous avez réunies ensemble pour les raisons si curieuses indiquées dans votre préface. Même si vous m'aviez pas eu ces raisons, nous n'aurions été que trop heureux d'avoir ensemble une piéce d'une inspiration si neuve et méditation d'une pareille intensité. Votre 
notion de "fidélité créatice" m'a beaucoup frappé, sans toutefois que j'arrive à la "réaliser" pleinement. Ainsi que je vous l'écrivais, je crois, à propos de votre "Journal de Métaphysique", je ne vous comprendrai tout à fait que lorsque j'aurais réussi à situer votre poin de vue par rapport au mien. Mais il fraudra pour cela que je vous relise de plus près, et peut-être la plume à la main. Je me borne, pour le moment, à vous dire avec quel intéret j'ai lu votre nouvelle oeuvre, très forte, très originale, et je vous prie de croire à mes sentiments tout dévoués.

\section{H. Bergson}

\section{Carta 2}

Paris, 9 de maio de 1934

O estado de minha saúde me deixa pouco tempo no meu dia para trabalhar e escrever. Então, eu só pude ler rápido e superficialmente, muito tardiamente também, o livro que você tem gentilmente me endereçado: "O mundo partido" com "Posição do mistério ontológico". Mas esta primeira leitura, que deve ser seguida por outra mais profunda (que acontecerá seguramente se eu encontrar alguma liberdade), foi suficiente para me mostrar a importância e o valor dos dois trabalhos que você reuniu em conjunto pelas mesmas razões curiosas indicadas em seu prefácio. Mesmo se você não tivesse essas razões, teríamos ficado muito felizes em ter em conjunto uma peça de uma inspiração nova e uma meditação de uma similar intensidade. Sua noção de "fidelidade criadora" me impressionou muito, mas eu não cheguei a "realizá-la" plenamente. Como eu escrevi para você, eu acredito, a propósito de seu "Diário Metafísico", que eu não compreendi completamente até que eu tenha sido capaz de situar o seu ponto de vista em relação ao meu. Mas é preciso, para isso, que eu vos releia mais de perto, e, talvez, sob a pena na mão. Limito-me, por enquanto, a dizer-lhe com que interesse eu li o seu novo trabalho, muito forte, muito original, e peço-lhe que acredite em meus sentimentos mais devotados.

H. Bergson

\section{Lettre 3}

Mon cher Collègue,

Je ne puis vous dire à quel point je suis touché de ce vous avez bien voulu écrire au sujet de mon livre: «La Pensée et le Mouvant». Vous avez admirablement compris ce que j'ai voulu faire. L'ai-je fait, et mon œuvre mérite-t-elle l'appréciation que vous en donnez dans une conclusion qui m'émeut profondément? Ce serait, certes, une joie inexprimable pour moi que de pouvoir réellement tenir, au moment de m'en aller, le langage que vous voulez bien me prêter. Vous parlez de l' «Esprit de 
la Musique». Combien je souhaite que vous écriviez, sur cet Esprit, le livre ou l'article que vous me semblez prédestiné à écrire! Merci et três amicalement à vous.

Paris, 2 de Julho 1934

\section{Carta 3}

Paris, 2 de julho de 1934

Meu caro Colega,

Eu não posso te dizer até que ponto eu estou tocado pelo que você gentilmente escreveu sobre o tema do meu livro, "O Pensamento e o Movente". Você compreendeu admiravelmente o que eu queria fazer. Eu fiz isto, e minha obra merece a apreciação que você dá a ela em uma conclusão que me afeta profundamente? Seria certamente uma alegria indescritível para mim de poder realmente tomar, quando eu vou, a linguagem que você quer me emprestar. Você fala do "Espírito da Música". Quanto desejo que você escreva, sobre este Espírito, o livro ou artigo que você me parece predestinado a escrever! Muito amigavelmente a você, obrigado.

H. Bergson

\section{Lettre 4}

Cher Collègue et ami,

Je viens de lire «Être et Avoir», et je tiens à vous dire la vive impression que ce livre a faite sur moi. Vous êtes l'inventeur d'un «genre», comme disent des historiens de la littérature: vous avez crée le «journal métaphysique», celui qui note tous les jours des impressions, mais des impressions qui ne viennent ni des sens ni même de la conscience telle qu'on l'entend d'ordinaire. Ce sont bien des impressions métaphysiques. D’où vous viennent-elles? Je crois en apercevoir l'origine dans l'implication que vous découvrez imméditament de quelque réalité suprasensible dans tel ou tel état d'ame, dont quelque chose subsiste une fois que vous avez éliminé tout ce qui concerne les corps, d'une part, et, d'autre part la surface de l'âme. Mais ici votre livre deviendrait plus clair pour moi si vous réunissiez vos pensées par un trait continu, - sans aller jusqu'à en faire, bien entendu, un tout systématique. Il est vrai que, j'ai peut-être tort de désirer une continuité plus grande, qui risquerait d'altérer la nature des parties ainsi raccordées entre elles. La verité est que j'ai besoin de vous relire, de vous relire de près, de beaucoup plus près que je n'ai pu le faire jusqu'à présent. Dés à présent, cependant, je biens à vous féliciter de d'avoir écrit ce livre, d'y avoir mis tant de force et de pénétration, et je vous renouvelle l'expression de mes sentiments tout dévoués.

Paris, 11 de Junho de 1935 


\section{Carta 4}

Paris, 11 de junho de 1935

Caro Colega e amigo,

Acabei de ler "Ser e Ter" e quero contar-lhe a viva impressão que este livro causou em mim. Você é o inventor de um "gênero", como dizem os historiadores da literatura: você criou o "diário metafísico", que anota impressões diárias, mas impressões que não vêm nem dos sentidos nem mesmo da consciência tal como se entende ordinariamente. Estas são bem impressões metafísicas. De onde você tem tirado elas? Eu creio em perceber a origem na implicação que você descobre imediatamente em alguma realidade suprassensível em tal ou tal estado da alma, do qual alguma coisa subsiste uma vez que você tem eliminado tudo o que concerne os corpos, de uma parte, e, de outra, a superfície da alma. Mas aqui seu livro se tornaria mais claro para mim se você reunisse seus pensamentos por uma linha contínua, sem ir tão longe a ponto de fazer, bem entendido, um todo sistemático. É verdade que, eu talvez posso estar errado ao desejar uma continuidade maior, que arriscaria alterar a natureza das partes assim conectadas umas às outras. A verdade é que preciso relê-lo, relê-lo de perto, muito mais perto do que consegui fazer até agora. De agora em diante, porém, felicito-o por ter escrito este livro, por ter colocado tanta força e penetração nele, e renovo a você a expressão de meus sentimentos mais devotados.

H. Bergson 